\title{
¿CUÁNTO LE CUESTA LA INFORMALIDAD AL SISTEMA DE SALUD COLOMBIANO?
}

Carolina María Londoño Montoya Universidad de Valencia España

Jhoana Marcela Gómez Muñetón Universidad de Antioquia Colombia

Yennifer Ester Celín Camargo Universidad de Antioquia Colombia

Jairo Humberto Restrepo Zea Universidad de Antioquia Colombia 
Panorama Económico, Vol. 27 - No. 3 (Julio - Septiembre de 2019), pp. 598-630

Carolina María Londoño Montoya

Jhoana Marcela Gómez Muñetón

Yennifer Ester Celín Camargo

Jairo Humberto Restrepo Zea

\title{
¿Cuánto le cuesta la informalidad al sistema de salud colombiano?
}

\section{Resumen}

El sistema de salud colombiano es de naturaleza pública y solidaria en cuanto al financiamiento, y busca la cobertura universal mediante la afiliación de la población a través de la contribución o del subsidio. Entre la población afiliada se encuentran quienes de acuerdo a sus niveles de ingresos deberían contribuir y no lo hacen, lo cual genera una pérdida que ocasiona un desequilibrio en el sistema. En este artículo se calcula la pérdida que puede experimentar el sistema cuando deja de percibir estas contribuciones, utilizando la Gran Encuesta Integrada de Hogares (GEIH) del Departamento Administrativo Nacional de Estadística (DANE), correspondiente al periodo 2008-2013. Los resultados indican que la pérdida para el año 2013 estuvo entre 2,7 y 2,9 billones de pesos colombianos, siendo los trabajadores por cuenta propia los principales causantes de la pérdida que se genera en el sistema de salud. La pérdida para el Sistema General de Seguridad Social en Salud (SGSSS) ha sido significativa, de modo que la informalidad aparte de representar un importante costo financiero, reduce la productividad de la economía.

Palabras clave: Informalidad, sistema de salud, financiamiento de la salud, subsidios, contribuciones sociales

\section{Combien coûte l'informalité au système colombien de santé?}

\section{Résumé:}

Le système de santé colombien est de nature publique et solidaire en termes de financement, et recherche une couverture universelle par l'affiliation de la population à travers la cotisation ou la subvention. Parmi la population affiliée, il y a ceux qui, selon leur niveau de revenu, devraient contribuer et ne pas contribuer, ce qui génère une perte qui entraîne un déséquilibre dans le système. Cet article calcule la perte que le système peut subir lorsqu'il cesse de recevoir ces contributions, à l'aide de la grande enquête intégrée auprès des ménages (GEIH) du Département administratif national des statistiques (DANE), correspondant à la période 2008-2013. Les résultats indiquent que la perte pour 2013 se situait entre 2,7 et 2,9 milliards de pesos colombiens, les travailleurs indépendants étant les principales causes de la perte générée dans le système de santé. La perte pour le système général de sécurité sociale de la santé (SGSSS) a été importante, de sorte que l'informalité, en plus de représenter un coût financier important, réduit la productivité de l'économie.

Mots clés: Informalité, système de santé, financement de la santé, subventions, contributions sociales

\section{How much does the informality to the colombian health system cost?}

\begin{abstract}
The Colombian health system is of a public and solidarity nature in terms of financing, and seeks universal coverage through the affiliation of the population through the contribution or subsidy. Among the affiliated population are those who according to their income levels should contribute and do not, which generates a loss that causes an imbalance in the system. This article calculates the loss that the system may experience when it ceases to receive these contributions, using the Large Integrated Household Survey (GEIH) of the National Administrative Department of Statistics (DANE), corresponding to the period 2008-2013. The results indicate that the loss for 2013 was between 2.7 and 2.9 billion Colombian pesos, with the selfemployed being the main causes of the loss that is generated in the health system. The loss for the General Health Social Security System (SGSSS) has been significant, so that informality apart from representing a significant financial cost, reduces the productivity of the economy.
\end{abstract}

Keywords: Informality, health system, health financing, subsidies, social contributions 


\title{
¿Cuánto le cuesta la informalidad al sistema de salud colombiano?
}

\author{
Carolina María Londoño Montoya' \\ Universidad de Valencia, España \\ Jhoana Marcela Gómez Muñetón² \\ Universidad de Antioquia, Colombia \\ Yennifer Ester Celín Camargo ${ }^{3}$ \\ Universidad de Antioquia, Colombia \\ Jairo Humberto Restrepo $\mathrm{Zea}^{4}$ \\ Universidad de Antioquia, Colombia
}

INFORMACIÓN DEL ARTÍCULO

Recepción del artículo: 17/01/2019

Concepto de evaluación: 20/05/2019

Aceptación del artículo: 1 / 06/2019

\section{INTRODUCCIÓN}

Colombia se caracteriza por tener un sistema de seguridad social que busca la cobertura universal en salud mediante un seguro público y solidario. El aseguramiento o afiliación al sistema se logra mediante dos regímenes: el contributivo y el subsidiado. El primero está asociado con la obligación de cotizar al sistema por parte de los trabajadores y sus empleadores, así como de los independientes con capacidad de pago y los pensionados, para obtener así cobertura de riesgos y contribuir a financiar a las personas que no tienen capacidad de pago o cuya cotización no alcanza a cubrir el costo del seguro. El régimen subsidiado fue diseñado para las personas que no cuentan con los recursos suficientes para financiar su afiliación, así que esta se financia con el aporte solidario del régimen contributivo y con recursos fiscales. Las personas beneficiarias del régimen subsidiado son seleccionadas mediante el Sistema de Selección de Beneficiarios (SISBÉN), con el cual se identifica a los potenciales beneficiarios de programas sociales dado su nivel de pobreza.

\footnotetext{
1. Carolina María Londoño Montoya, Magíster en Finanzas Corporativas, Universidad de Valencia (España). carolondono89@gmail.com

2. Jhoana Marcela Gómez Muñetón, Economista, Universidad de Antioquia. magomu1113@hotmail.com

3. Yennifer Ester Celín Camargo, Economista, Universidad de Antioquia. Investigadora asociada al Grupo de Estudios Regionales de la Facultad de Ciencias Económicas, Universidad de Antioquia. yennicelin@hotmail.es 4. Jairo Humberto Restrepo Zea, Magíster en Gobierno y Asuntos Públicos, FLACSO (México), Profesor Titular de la Facultad de Ciencias Económicas, Universidad de Antioquia. jairo.restrepo@udea.edu.co
} 
Los recursos que financian el sistema de salud provienen de las contribuciones de los trabajadores, de los pensionados y de los independientes, los aportes de los empleadores, los recursos fiscales nacionales y de los entes territoriales, y algunos recursos que provienen de la prestación de servicios y que buscan controlar fenómenos de riesgo moral o complementar la financiación de la atención de la población beneficiaria (cuotas moderadoras y copagos)..$^{5}$ Según el Boletín de Cifras Financieras del Sector Salud, del Ministerio de Salud y Protección Social, para el bimestre noviembre-diciembre de 2013 la mayor participación en la financiación del sistema la tenían las cotizaciones, aportando un 52,2\% de los recursos, seguidos de los recursos del Sistema General de Participaciones (SGP) que representan $20 \%$ y de los excedentes financieros del Fondo de Solidaridad y Garantía -FOSYGA-, con un 10,2\%.

Ahora bien, la reforma tributaria de 2012 (Ley 1607), estableció a partir de 2014 la sustitución parcial de los aportes patronales, que correspondía 8,5 puntos de la cotización total (12,5\% del ingreso base de cotización) y cuyos puntos restantes $(4,0)$ seguirán a cargo de los trabajadores. Esta medida está dirigida de manera exclusiva a las empresas del sector privado, y dentro de estas para los trabajadores que devenguen menos de diez salarios mínimos. Los recursos que dejan de percibirse mediante vía de la cotización se espera que sean compensados mediante el impuesto sobre la renta para la equidad, denominado CREE, establecido por la misma ley.

La forma de financiar la seguridad social da cuenta del vínculo de ésta con el mercado laboral. El hecho de que el aseguramiento en salud esté asociado a la situación laboral de las personas ocasiona varios efectos: por un lado, se incrementan los costos no salariales que debe asumir el empleador, y por otro, se generan incentivos que influyen en las decisiones de los individuos en el mercado laboral, principalmente las asociadas a la participación laboral y al tipo de ocupación que se elige (Fedesarrollo, 2011).

El costo que representa para el empleador afiliar a una persona a la seguridad social en salud actúa como un impuesto al trabajo, y dada la presencia de un salario mínimo, es difícil que el impuesto pueda ser trasladado al trabajador o dividido entre ambos. La imposibilidad de trasladar el impuesto reduce la cantidad de empleo que se demanda, ocasionando un incremento del desempleo y de la informalidad, así como la segmentación del mercado laboral. Los efectos finales en las diferentes variables dependen de factores como la valoración que hacen los empleados de los beneficios recibidos, de la facilidad con que se puedan evadir los impuestos o de la existencia de programas que ofrecen beneficios similares o iguales a los que se financian con el impuesto, como el régimen subsidiado para el caso de Colombia (Bernal y Guitierrez, 2012).

De manera similar, como una parte de las contribuciones es asumida por los trabajadores, estos pueden verse desincentivados a participar en el mercado laboral, mucho más en un contexto en el que pueden obtener beneficios del régimen subsidiado sin pagar por ellos, y que luego de la sentencia T-760 de 2008 de la Corte Constitucional se ha puesto en marcha lo establecido en la Ley 100 de 1993, en el sentido de igualar los planes de beneficio de ambos regímenes.

\footnotetext{
5. El Sistema General de Seguridad Social en Salud, creado por la Ley 100 de 1993, funciona mediante un esquema de competencia regulada que permite que aseguradoras privadas, públicas o mixtas (empresas promotoras de salud -EPS-), garanticen la cobertura en salud mediante la prestación de servicios que contratan con las instituciones prestadoras de servicios -IPS-
} 
Parece entonces que una financiación de la seguridad social vía impuestos a la nómina puede incrementar la informalidad. Esto hace que muchos trabajadores dejen de contribuir a la salud y a otros fondos de protección social, ocasionando una disminución en los recursos que el sistema tenía previsto percibir, disminuyendo la cantidad de personas que están afiliadas al régimen contributivo y ejerciendo una mayor presión sobre el régimen subsidiado. La Ley 100 se hizo sobre la previsión de que dos tercios de la población estarían afiliados al régimen contributivo y solo un tercio al subsidiado, pero desde 2008 la población afiliada al régimen subsidiado era cercana al 50\% muy similar a la del contributivo (Clavijo \& Torrente, 2008).

Es así como en este trabajo se pretende calcular la pérdida potencial que experimenta el sistema cuando deja de percibir contribuciones por personas que se encuentran laborando en el sector informal y que idealmente deberían pertenecer al sector formal. Se busca así brindar un análisis detallado de lo que implica tener unas altas tasas de informalidad, contribuyendo al debate sobre cómo el mercado informal afecta el desarrollo de la economía, especialmente el desenvolvimiento del sistema de salud. El trabajo consta de cinco secciones, además de esta introducción. En la segunda sección se presenta el marco teórico, con una revisión del concepto de informalidad, las formas de medirla, cómo se presenta en Colombia y algunos problemas que incentivan la informalidad. La tercera sección está dedicada a la metodología, en esta se explica cómo se calcula la perdida por medio de los datos de la Gran Encuesta Integrada de Hogares (GEIH), proporcionada por el DANE. En la cuarta sección se presentan los resultados, con los cálculos de la pérdida del sistema entre 2008-2013. Y en la quinta sección se mencionan las conclusiones, con la importancia que tiene la informalidad en el costo financiero del sistema de salud, y se plantean algunas recomendaciones de política.

\section{MARCO TEÓRICO Y REVISIÓN DE LITERATURA}

\section{Concepto de informalidad}

La informalidad es una situación en la que las empresas y los trabajadores no cumplen con ciertas regulaciones o infringen las leyes, no reportan sus actividades, no están registradas oficialmente ante las instituciones estatales u operan por fuera de los circuitos de la economía moderna. También es entendida como una situación en la cual los trabajadores no cuentan con condiciones adecuadas para llevar a cabo su actividad, como salud ocupacional, seguridad en el trabajo, entre otras, asociadas a la evasión de impuestos y regulaciones por parte de las empresas, como una característica estructural de los mercados laborales de los países en desarrollo, e incluso como una tendencia de los mercados en el marco de la globalización. En la literatura económica se encuentran varios efectos adversos asociados a la informalidad, como malas condiciones de trabajo, bajos niveles de productividad, bajos niveles de ingreso e incumplimiento de las leyes, entre otros (Perry et al., 2007).

Se reconocen dos enfoques para aproximarse al concepto de informalidad: el estructuralista y el institucionalista (Ver Tabla 1). El enfoque estructuralista considera que la informalidad es una característica de los mercados que responde a los niveles de producción y de productividad de la economía y al tamaño de la empresa óptimo que puede operar en las economías en desarrollo, y el enfoque institucionalista atribuye la informalidad a la excesiva regulación, a las normas impuestas por el Estado, a las altas cargas fiscales y a la institucionalidad (Uribe y Ortiz, 2006). 
Tabla 1.

Informalidad: enfoque estructuralista y enfoque institucionalista

\begin{tabular}{l|l}
\hline Enfoque estructuralista & Enfoque institucionalista \\
\hline
\end{tabular}

La informalidad se explica principalmente por el escaso desarrollo del sector moderno de la economía.
Se centra en los costos que el Estado y en general las instituciones imponen al funcionamiento, la legalización y el desempeño de las empresas.
Los mercados están segmentados por sus características estructurales, el sector moderno y el sector informal.
La legislación que impone el Estado distorsiona la economía y genera informalidad.
El énfasis está en las limitaciones de la demanda laboral.
El énfasis está en la escogencia de los trabajadores (lado de la oferta).

Enfoque desde la macroeconomía.

Enfoque desde la microeconomía.

La informalidad es producto de la divergencia, tanto cuantitativa como cualitativa, entre la oferta y la demanda de trabajo.
La informalidad es ocasionada por un proceso de elección racional de los agentes sobre su participación en la actividad económica.

Fuente: Elaboración propia a partir de Uribe y Ortiz (2006).

Además, existen diversas visiones o perspectivas para abordar el estudio de la informalidad. Algunos estudios analizan la informalidad desde una perspectiva empresarial, con base en el tamaño de la empresa, considerando que generalmente las empresas pequeñas - con cinco o menos trabajadores- son informales, ya sea porque su nivel óptimo de operación está en ese nivel y no se justifica para ellos operar en la formalidad, o porque la informalidad es un estado de la evolución o del proceso de desarrollo de la empresa. Otra perspectiva, la laboral, considera la informalidad desde las condiciones y las garantías laborales de cada trabajador, independientemente de la empresa, la afiliación a ciertos beneficios y las contribuciones a salud, pensiones y riesgos laborales, entre otros (Uribe y Ortiz, 2006).

La informalidad ha estado asociada tradicionalmente con un mecanismo de exclusión de los beneficios del Estado, tanto para empresas como para trabajadores, de sus garantías y de la participación en la economía formal, con base en argumentos de segmentación del mercado laboral, de elevadas regulaciones y de altas cargas fiscales que las empresas no 
pueden asumir. Sumado a esto, se ha asimilado la informalidad a una vía de escape en la que individuos y organizaciones realizan un análisis costo-beneficio de los servicios que les provee el Estado y la institucionalidad, y la capacidad de estos para ofrecerles garantías; cuando la valoración de los servicios estatales es baja, se escapa de la formalidad para incursionar en el mundo de lo informal (Perry et al., 2007).

Para efectos de este trabajo, y basados en las perspectivas de los diferentes actores, se considera que la informalidad es ocasionada por los incentivos que generan en los agentes la legislación, la estructura del sistema de seguridad social y los impuestos asociados al mercado laboral, lo que influye en sus decisiones de ingresar o no a los mercados laborales, pero todo esto dentro de una estructura económica con bajos niveles de productividad y altos niveles de pobreza donde no se desarrollan las condiciones para formalizarse, ni se ofrecen incentivos más fuertes a los que generan las cargas impositivas. Por el contrario, algunos programas sociales como el régimen subsidiado, se comportan como un subsidio a la informalidad.

\section{¿Cómo se mide la informalidad?}

Existen los métodos macroeconómicos, los cuales consideran por ejemplo la diferencia entre los ingresos formales reportados y los datos obtenidos de encuestas o de auditorías, las diferencias entre el pago efectivo de impuestos y las percepciones sobre el nivel de cumplimiento de estos por parte de los trabajadores. Existen también métodos indirectos para calcular medidas de informalidad, como el consumo de energía eléctrica y componentes inexplicados de la demanda monetaria (Perry et al., 2007). Se han empleado diversos criterios teniendo en cuenta los datos disponibles y el enfoque particular que se asuma para medir la informalidad. Una forma de hacerlo es calculando la proporción de empleados que trabajan en empresas con menos de cinco trabajadores con respecto al número de empleados totales. Otra es la proporción de empleados que no tienen acceso a seguridad social ni a pensiones.

Para América Latina resulta complejo el análisis de la informalidad debido a que no existe una medición común. La Tabla 2 muestra las diferencias fundamentales entre las medidas de informalidad más utilizadas por la literatura. La razón por la que estas medidas de informalidad no son homogéneas no es caprichosa, y casi siempre responde a disposiciones legales relativas a los sistemas de seguridad social de cada país. Como se observa en el Tabla 3 países como Argentina y Brasil, que cuentan con servicios de salud pública generalizados y no contributivos, no se tiene la pregunta de si los trabajadores realizan cotizaciones a salud y la informalidad se mide de acuerdo a las cotizaciones a pensiones (en Uruguay también). En el resto de países estudiados, la medida más implementada es la de cotizaciones a salud, y para hacer la exclusión de la formalidad a los trabajadores beneficiarios de los aportes de seguridad social de un familiar, se indagó por los aportes que realiza la firma a nombre del trabajador o como el caso particular de Colombia, que se elimina explícitamente del grupo de formales a los trabajadores que se declaran beneficiarios del sistema de salud (Fernández et al., 2017). 
Tabla 2.

\section{Medidas oficiales y generalizadas de informalidad para un grupo de países}

\begin{tabular}{|c|c|c|c|c|}
\hline Conceptos & Perú & Colombia & Brasil & México \\
\hline $\begin{array}{l}\text { Asalariados } \\
\text { públicos y } \\
\text { privados y } \\
\text { servicios } \\
\text { domésticos }\end{array}$ & $\begin{array}{l}\text { Seguridad social } \\
\text { no financiada } \\
\text { por el empleador }\end{array}$ & $\begin{array}{l}\text { No aporta a } \\
\text { salud/pensión }\end{array}$ & No tiene CTPS ${ }^{6}$ & $\begin{array}{l}\text { Por parte del } \\
\text { trabajo no } \\
\text { tiene acceso a } \\
\text { atención médica }\end{array}$ \\
\hline $\begin{array}{l}\text { Empleados } \\
\text { públicos }\end{array}$ & $\begin{array}{l}\text { Seguridad social } \\
\text { no financiada } \\
\text { por el empleador }\end{array}$ & $\begin{array}{l}\text { No aporta a } \\
\text { salud/pensión }\end{array}$ & $\begin{array}{l}\text { No tiene CTPS y } \\
\text { o son ni militares } \\
\text { ni servidores } \\
\text { públicos } \\
\text { estatutarios }\end{array}$ & $\begin{array}{l}\text { Por parte del } \\
\text { trabajo no } \\
\text { tiene acceso a } \\
\text { atención médica }\end{array}$ \\
\hline $\begin{array}{l}\text { Servicios } \\
\text { domésticos }\end{array}$ & $\begin{array}{l}\text { Seguridad social } \\
\text { no financiada } \\
\text { por el empleador }\end{array}$ & $\begin{array}{l}\text { No aporta a } \\
\text { salud/pensión }\end{array}$ & No tiene CTPS & $\begin{array}{l}\text { Por parte del } \\
\text { trabajo no } \\
\text { tiene acceso a } \\
\text { atención médica }\end{array}$ \\
\hline $\begin{array}{l}\text { Familiares } \\
\text { no asalariados }\end{array}$ & $\mathrm{Si}$ & $\begin{array}{l}\text { No aporta a } \\
\text { salud/pensión }\end{array}$ & $\mathrm{Si}$ & $\mathrm{Si}$ \\
\hline $\begin{array}{l}\text { Otros } \\
\text { trabajadores } \\
\text { no asalariados }\end{array}$ & $\mathrm{Si}$ & $\begin{array}{l}\text { No aporta a } \\
\text { salud/pensión }\end{array}$ & $\mathrm{Si}$ & $\begin{array}{l}\text { Por parte del } \\
\text { trabajo no } \\
\text { tiene acceso a } \\
\text { atención médica }\end{array}$ \\
\hline Empleadores & $\begin{array}{l}\text { Trabaja en el } \\
\text { sector informal }\end{array}$ & $\begin{array}{l}\text { No aporta a } \\
\text { salud/pensión }\end{array}$ & No & $\begin{array}{l}\text { Trabaja en el } \\
\text { sector informal }\end{array}$ \\
\hline Cuenta propia & $\begin{array}{l}\text { Trabaja en el } \\
\text { sector informal }\end{array}$ & $\begin{array}{l}\text { No aporta a } \\
\text { salud/pensión }\end{array}$ & $\mathrm{Si}$ & $\begin{array}{l}\text { Trabaja en el } \\
\text { sector informal } \\
\text { o agropecuario } \\
\text { de subsistencia }\end{array}$ \\
\hline
\end{tabular}

6. Según el Ministerio de Trabajo de Brasil el termino Carteira de Trabalho e Previdência Social (CTPS) "es un documento obligatorio para todas las personas que van a prestar algún tipo de servicio, sea en la industria, el comercio, en agricultura, en la ganadería o incluso de naturaleza doméstica." 
Tabla 2.

Medidas oficiales y generalizadas de informalidad para un grupo de países

\begin{tabular}{|c|c|c|c|}
\hline Conceptos & Argentina & Uruguay & Chile \\
\hline $\begin{array}{l}\text { Asalariados } \\
\text { públicos y } \\
\text { privados y } \\
\text { servicios } \\
\text { domésticos }\end{array}$ & $\begin{array}{l}\text { No aporta } \\
\text { a jubilación }\end{array}$ & $\begin{array}{l}\text { No aporta a } \\
\text { jubilación } \\
\text { y no es } \\
\text { subempleado }\end{array}$ & $\begin{array}{l}\text { El empleo le otórga cotización } \\
\text { por previsión de salud o de } \\
\text { pensión o sin contrato escrito, } \\
\text { o sin liquidación de sueldo, o } \\
\text { contratado por contratista }\end{array}$ \\
\hline $\begin{array}{l}\text { Empleados } \\
\text { públicos }\end{array}$ & $\begin{array}{l}\text { No aporta } \\
\text { a jubilación }\end{array}$ & $\begin{array}{l}\text { No aporta a } \\
\text { jubilaciones } \\
\text { y no es } \\
\text { subempleado }\end{array}$ & $\begin{array}{l}\text { El empleo le otorga cotización por } \\
\text { previsión de salud o de pensión } \\
\text { o sin contrato escrito, o sin } \\
\text { liquidación de sueldo, o contratado } \\
\text { por contratista }\end{array}$ \\
\hline $\begin{array}{l}\text { Servicios } \\
\text { domésticos }\end{array}$ & $\begin{array}{l}\text { No aporta } \\
\text { a jubilación }\end{array}$ & $\begin{array}{l}\text { No aporta a } \\
\text { jubilaciones } \\
\text { y no es } \\
\text { subempleado }\end{array}$ & $\begin{array}{l}\text { El empleo le otorga cotización por } \\
\text { previsión de salud o de pensión o } \\
\text { sin contrato escrito, o sin liquidación } \\
\text { de sueldo, o contratado } \\
\text { por contratista }\end{array}$ \\
\hline
\end{tabular}

\begin{tabular}{lll}
\hline Familiares & Si & $\begin{array}{l}\text { No aporta a } \\
\text { jubilaciones } \\
\text { no asalariados } \\
\text { subempleado }\end{array}$
\end{tabular}

\begin{tabular}{llll}
\hline $\begin{array}{l}\text { Otros } \\
\text { trabajadores } \\
\text { no asalariados }\end{array}$ & Si & $\begin{array}{l}\text { No aporta a } \\
\text { jubilaciones } \\
\text { y no es } \\
\text { subempleado }\end{array}$ & Si \\
\hline Empleadores & $\begin{array}{l}\text { No aporta a } \\
\text { mono-tributo }\end{array}$ & $\begin{array}{l}\text { No aporta a } \\
\text { jubilaciones } \\
\text { y no es } \\
\text { subempleado }\end{array}$ & Empresas privadas con \\
menos de cinco ocupados & \\
\hline Cuenta propia & $\begin{array}{l}\text { No aporta a } \\
\text { mono-tributo }\end{array}$ & $\begin{array}{l}\text { No aporta a } \\
\text { jubilaciones } \\
\text { y no es } \\
\text { subempleado }\end{array}$ & Todos los que no son \\
& técnicos o profesionales
\end{tabular}

Fuente: Elaboración propia a partir de Fernández et al., (2017). 
En las medidas utilizadas para medir la informalidad de los trabajadores independientes y no remunerados también se encuentran diferencias y estas tienden a ser explicadas por la legislación de cada país. Entre tanto, en Brasil todos los trabajadores cuentapropia se consideran informales; la informalidad de los trabajadores independientes se determina en Colombia y Uruguay por las cotizaciones, y en México y Perú los trabajadores independientes no están obligados a cotizar, y la informalidad se mide de acuerdo a su pertenencia al sector informal, que es una medida más consecuente con las recomendaciones recientes de la Organización Internacional del Trabajo (OIT) (Fernández et al., 2017).

Tabla 3.

Especialidades del sistema de salud de siete países para 2015

\begin{tabular}{|c|c|c|c|c|c|c|c|}
\hline Conceptos & Perú & Colombia & Brasil & México & Argentina & Uruguay & Chile \\
\hline $\begin{array}{l}\text { Salud subsidiada } \\
\text { generalizada (100\% } \\
\text { de cobertura de } \\
\text { servicios públicos) }\end{array}$ & No & No & $\mathrm{Si}$ & No & $\mathrm{Si}$ & No & No \\
\hline $\begin{array}{l}\text { Es obligatorio para } \\
\text { cuenta propia cotizar } \\
\text { a salud/pensiones }\end{array}$ & No & $\mathrm{Si}$ & $\mathrm{Si}$ & No & $\begin{array}{l}\text { No } \\
\text { en } \\
\text { salud }\end{array}$ & $\mathrm{Si}$ & $\mathrm{No} / \mathrm{Si}$ \\
\hline $\begin{array}{l}\text { Es obligatorio cotizar } \\
\text { a pensiones cuando } \\
\text { se cotiza a salud }\end{array}$ & No & $\mathrm{Si}$ & $\begin{array}{l}\text { No } \\
\text { aplica }\end{array}$ & $\mathrm{Si}$ & No & $\mathrm{Si}$ & $\mathrm{Si}$ \\
\hline $\begin{array}{l}\text { Edad de pensión } \\
\text { mujeres }\end{array}$ & 65 & 57 & 60 & 65 & 60 & 60 & 65 \\
\hline $\begin{array}{l}\text { Edad de pensión } \\
\text { hombres }\end{array}$ & 65 & 62 & 65 & 65 & 65 & 60 & 60 \\
\hline $\begin{array}{l}\text { Número de años para } \\
\text { conseguir una pensión } \\
\text { contributiva }\end{array}$ & 20 & 23.5 & $30 / 35$ & 25 & 30 & 30 & \\
\hline $\begin{array}{l}\text { Conyugue es } \\
\text { beneficiaria del } \\
\text { sistema de salud }\end{array}$ & $\mathrm{Si}$ & $\mathrm{Si}$ & $\mathrm{Si}$ & $\mathrm{Si}$ & $\mathrm{Si}$ & $\begin{array}{c}\mathrm{Si} \\
\text { (desde } \\
2010)\end{array}$ & $\mathrm{Si}$ \\
\hline
\end{tabular}

Fuente: Elaboración propia a partir de Fernández et al., (2017). 
En Colombia, la medición oficial de la informalidad laboral ha estado determinada por los lineamientos de la OIT, lo que ha llevado al DANE a revelar la información oficial sobre la informalidad laboral. De esta manera, el documento metodológico que contiene el cálculo sobre informalidad laboral publicado por el DANE expresa que:

"La definición adoptada por el DANE, para la medición del empleo informal, se remite a la resolución de 1993 y las recomendaciones del grupo de DELHI, de las que se toman elementos que se ajustan a la realidad del mercado laboral colombiano. Estas indican que la aproximación a la medición de informalidad laboral en materia de personal ocupado en las empresas debe ser de cinco trabajadores, y en particular, toma otros que permiten precisar si un trabajador se encuentra trabajando en empleo informal. A continuación, se describen las características principales que hacen operativa la definición para el DANE: 1. Los empleados particulares y los obreros que laboran en establecimientos, negocios o empresas que ocupen hasta cinco personas en todas sus agencias y sucursales, incluyendo el patrono y/o socio; 2. Los trabajadores familiares sin remuneración; 3. Los trabajadores sin remuneración en empresas o negocios de otros hogares; 4. Los empleados domésticos; 5. Los jornaleros o peones; 6. Los trabajadores por cuenta propia que laboran en establecimientos hasta cinco personas, excepto los independientes profesionales; 7. Los patrones o empleadores en empresas de cinco trabajadores o menos; 8. Se excluyen los obreros o empleados del gobierno" (DANE, 2009, p.8).

Asimismo, el DANE toma los datos de informalidad de la Gran Encuesta Integrada de Hogares (GEIH) y de la Encuesta de Marco de Áreas (Microestablecimientos). Con los primeros mide el empleo informal, mientras que los segundos los emplea para medir el sector informal desde la perspectiva de las empresas familiares. El valor de informalidad que publican tiene en cuenta ambos criterios.

\section{La informalidad en Colombia}

En la Figura 1 se observa la tasa de empleo informal no agrícola en América Latina para el año 2013. Para este año Colombia ocupó el décimo lugar con un nivel de informalidad de 54,4\%, quedando por debajo de países como Brasil, Chile, Ecuador y México. Por su parte los países que presentaron menores niveles de informalidad fueron Costa Rica y Uruguay con un 30,7\% y 34,1\% respectivamente, mientras que los de mayor porcentaje fueron Honduras y Guatemala con un 72,8\% y 73,6\% respectivamente. 


\section{Figura 1. Tasa de Empleo Informal No Agrícola en América Latina 2013}

\section{Costa Rica \\ Uruguay \\ Brasil \\ Panamá \\ Argentina \\ Chile \\ Ecuador \\ R. Dominicana}

México

Colombia

Paraguay

Perú

El Salvador

Honduras

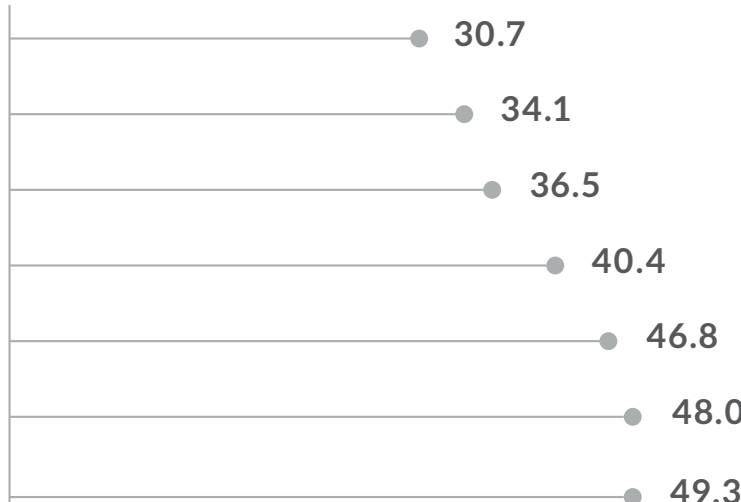

51.2

53.8

54.4

63.8

64.0

65.6

Fuente: Elaboración propia a partir de OIT 2014

De otro lado, se observa en la Figura 2 que la tasa de informalidad en Colombia en los últimos años presenta una ligera tendencia decreciente hasta el año 2007, y a partir de este año se produce un aumento hasta el año 2009. Según Cárdenas \& Mejía (2007), la informalidad ha aumentado en este período considerablemente desde finales de 2007 por factores relacionados con la crisis económica, así como por el aumento de la carga tributaria empresarial, teniendo en cuenta los costos laborales diferentes al salario. Además, durante el período 2001 a 2012 la informalidad muestra una correlación negativa de $-0,625940$ con respecto al PIB. Sin embargo, a partir de 2012 y hasta 2016 se presentó una correlación positiva de 0,550184. Este cambio se originó según la OIT (2014), por la combinación del crecimiento económico, las iniciativas legislativas y las reformas institucionales implementadas en los últimos años (Ver Anexo 1). Cabe resaltar que en las iniciativas legislativas la Reforma Tributaria de 2012 jugó un papel importante en este cambio. 
En el año 2012 fue aprobada la Ley 1607 de Reforma Tributaria, cuyos alcances entraron en vigencia entre mayo de 2013 y enero de 2014, en donde uno de sus principales objetivos es promover la creación y formalización de empleo a través de la reducción de los costos laborales, al sustituir el 12,5\% de aportes parafiscales sobre la nómina por un gravamen sobre las utilidades llamado CREE del 8\%. Para Fernández y Villar (2017), existe una estrecha relación entre la tasa de informalidad y los impuestos sobre la nómina. Sin embargo, se pueden encontrar otras variables que pueden afectar el comportamiento de la informalidad. Para el caso de Colombia se identificaron cinco factores importantes: un cambio general en los impuestos, en particular la creación de un impuesto sobre la renta (CREE) para sustituir contribuciones tributarias; en el periodo posterior a la reforma se evidenció un alto crecimiento económico; un incremento en el salario mínimo real; cambios en los empleos gubernamentales y anticipaciones de la reforma.

Figura 2. Evolución de la informalidad y crecimiento del PIB, 2001-2016

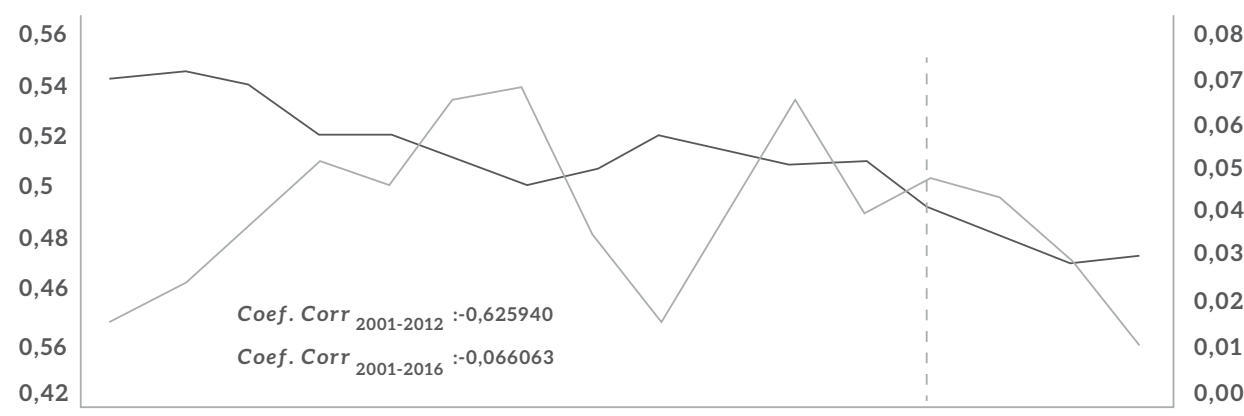

2001200220032004200520062007200820092010201120122013201420152016

- Informalidad

Crecimiento del PIB

Fuente: Elaboración propia a partir del DANE (2001-2016)

Para analizar el impacto que tuvo la Reforma Tributaria de 2012 se presentan a continuación dos estudios. En primer lugar, se encuentra el estudio realizado por Rodríguez (2014), en el cual por medio de un Modelo de Equilibrio General Computable (MEGC) de la economía colombiana se simula lo determinado en la Ley 1607 de 2012 de Reforma Tributaria, se pretende contribuir al debate de la parafiscalidad analizando los efectos macroeconómicos de su eliminación. En segundo lugar, se tiene el estudio realizado por Morales y Medina (2016), Para este análisis se utilizaron los datos administrativos de la Planilla Integrada de Liquidación de Aportes (PILA) con el cual se analiza el Impacto de la reducción en los impuestos a la nómina en el empleo formal. En términos generales todos los estudios científicos con los que se cuenta hasta el momento sobre el impacto de la reforma coinciden en que esta tuvo un efecto relevante sobre el empleo formal, no obstante, su magnitud no es específicamente grande. Para obtener mayores disminuciones de la tasa de informalidad se necesita un conjunto más amplio 
de medidas teniendo en cuenta los recortes adicionales de los costos no salariales, de tal forma que la retribución de la mano de obra sea cada vez más cercana a la productividad laboral (Colombia. Banco de la República, 2016).

Asimismo, se observa en la Figura 2 que en los años siguientes a la implementación de la Reforma el empleo informal ha disminuido, pasando de 0,51\% en 2012 a 0,47\% en 2016. Además, según Fernández y Villar (2017), entre el año 2012 y 2014 fueron creados alrededor de 871.000 empleos formales donde el 90\% son asalariados, cerca de 134.000 trabajadores por cuenta propia entraron en la población ocupada y 33.000 empleos informales desaparecieron. Por tal motivo se presenta en la Figura 3 que a partir de 2012 el empleo formal muestra un marcado crecimiento sostenido y desde 2014 hasta 2016 se observa que el empleo formal se encuentra por encima del empleo informal. También, se tiene que el crecimiento de los cotizantes en el periodo 2012 a 2016 con respecto a la tasa de ocupados ha oscilado entre el $5 \%$ y el $7 \%$, manteniendo una tendencia constante (Ver Figura 4). Por consiguiente, esto nos permite verificar que durante los años pos-Reforma se ha generado mayor empleo formal, mayor número de cotizaciones y menores niveles de informalidad con respecto a los años pre-Reforma, aunque el impacto en la creación de empleo formal ha sido moderado.

Figura 3. Trabajadores Formales e Informales, 2008 - 2016

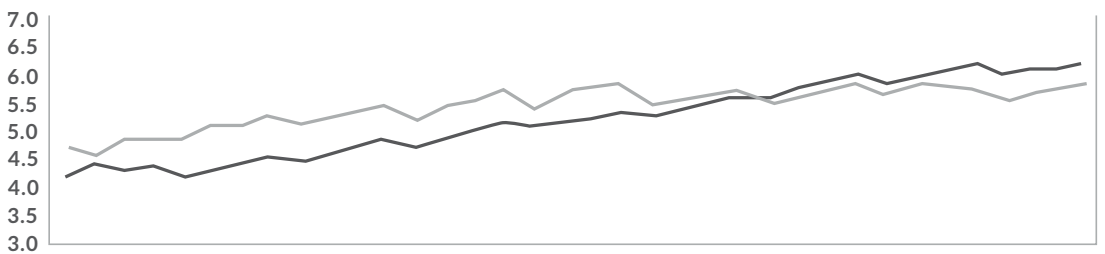

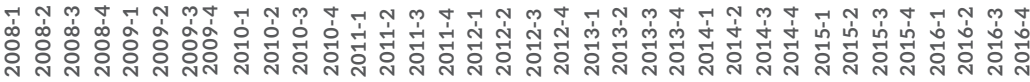

Empleos formales $\quad$ Empleos informales

Fuente: Elaboración propia a partir del DANE (2008-2016)

Figura 4. Tasa de Crecimiento cotizantes y ocupados, 2007 - 2016

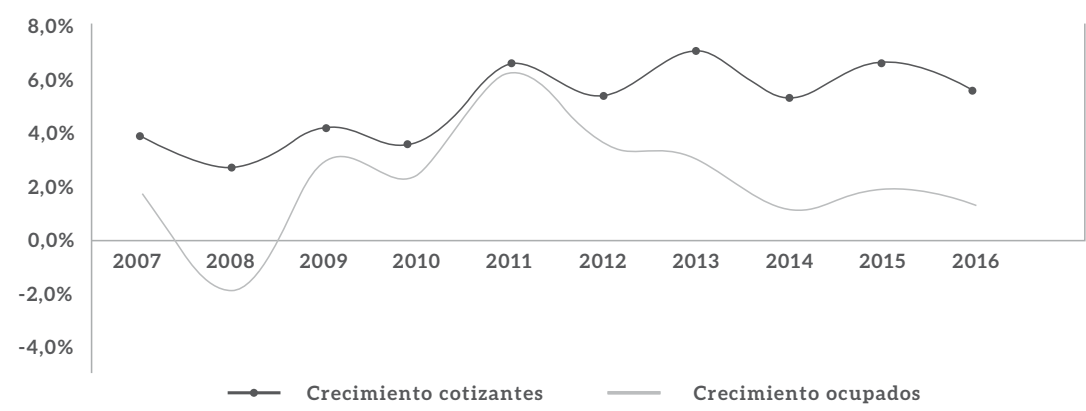

Fuente: Elaboración a partir del DANE (2007-2016) 


\section{Un problema de incentivos}

Cuando se habla de incentivos cabe mencionar dos casos en particular. Por el lado de la salud se hace referencia a los estímulos que crea la estructura del sistema, haciendo que los individuos actúen de una u otra forma. En este caso, tanto el régimen contributivo como el régimen subsidiado son caracterizados por generar cierto tipo de incentivos, lo cual crea una disyuntiva en la elección del régimen al que se quiere pertenecer. De otro lado se tienen los costos no salariales, los cuales desincentivan la contratación del empleo formal. Por esta razón es de vital importancia analizar las posibles causas que generan estas situaciones, con el fin de encontrar soluciones que ayuden a contrarrestar el efecto. El sistema de aseguramiento de salud está vinculado directamente al mercado laboral, a través de la afiliación obligatoria al régimen contributivo por parte de los empleados formales. Es por esto, que las decisiones de los individuos en el mercado laboral son afectadas por el tipo de reformas que se apliquen, como la introducida por la Ley 100 de 1993. Esto se puede ver reflejado en el caso de la existencia de los seguros, ya que estos pueden alterar desde la elección del tipo de ocupación hasta el hecho de participar o no en el mercado laboral por parte del individuo. La provisión de seguros es un ejemplo claro de los impactos que se generan, ya que este se puede convertir en un determinante fundamental para operar en el sector informal, si estos no tienen ningún costo, como es el caso de los que están afiliados al régimen subsidiado, por lo que este puede actuar como un subsidio a la informalidad (Fedesarrollo, 2011).

Se argumenta que la afiliación al régimen contributivo tiene un impacto sobre la participación laboral. Según Currie y Madrian (1999), los beneficios que se obtienen al estar empleado, debido a la seguridad social, aumentan la participación en el mercado laboral. Sin embargo, teniendo en cuenta que las personas que pertenecen al régimen contributivo pueden afiliar a sus familiares, el sistema puede también tener efectos sobre la participación laboral de estos. Las personas que son beneficiarias, no tienen los mismos incentivos para buscar un seguro de salud a través del empleo, dado que sus beneficios netos serán menores. De igual forma, la afiliación al régimen contributivo puede tener impactos sobre el tipo de ocupación escogida por los trabajadores, el cual depende del valor que este le otorgue a la salud, ya que si el valor es alto es más probable que el individuo trate de pertenecer al sector formal y ser asalariado. Por otro lado, teniendo en cuenta que parte de las contribuciones son asumidas por el trabajador y que además puede ver disminuido su salario por las contribuciones del empleador, el individuo se ve desincentivado a ser un empleado formal (Fedesarrollo, 2011).

El estar afiliado al régimen subsidiado tiene impacto sobre la participación laboral y sobre el tipo de ocupación de las personas. En Colombia, el hecho de tener un seguro gratuito, y en estos últimos años casi de igual cobertura al del régimen contributivo, afecta significativamente el tipo de ocupación elegida por los individuos, que podrían optar por ser informales o trabajar por cuenta propia. Además, el hecho de pertenecer al régimen subsidiado genera un efecto sustitución entre los gastos en salud y el consumo de otros bienes, lo que a su vez desincentiva la idea de conseguir un empleo formal y contribuir a salud. Este hecho se puede ver reflejado en el crecimiento acelerado de la afiliación al régimen subsidiado con respecto a la afiliación al régimen contributivo que ha sido mucho menor (Fedesarrollo, 2011).

Según el estudio realizado por Camacho, Conover y Hoyos (2013), en Colombia el aseguramiento público en salud, a través del régimen subsidiado, desincentiva el empleo 
formal. Sirviéndose de las diferentes fechas de implementación del SISBÉN y los datos sobre elegibilidad para los municipios, analizaron qué cambios estaban asociados a la entrada en vigencia del régimen subsidiado y cuáles no. Muestran estimaciones robustas y consistentes para sustentar un incremento del $4 \%$ en el empleo informal. Los principales hallazgos indican que los individuos en el margen optimizan la decisión de participar o no en el mercado formal. Este resultado indica que aproximadamente el 8\% de la fuerza laboral no entra al mercado formal y esto representa un incremento del $11 \%$ en los gastos del Gobierno en salud.

En la Tabla 4 los costos no salariales ${ }^{7}$ en los que incurre el empleador, el empleado formal y el trabajador independiente varían significativamente. Para el año 2013 la contribución a salud representa un $12,5 \%$, en donde un $8,5 \%$ es cubierto por el empleador y un $4 \%$ por el empleado formal. De la misma forma, la contribución a pensiones representa un 16\%, con un $12 \%$ a cargo del empleador y un $4 \%$ del empleado formal. En el caso del empleador, vemos que los costos no salariales representan aproximadamente un $30 \%$ del salario, dentro de los cuales se encuentra pago a salud, pensiones, riesgos profesionales, ICBF, SENA, cajas de compensación familiar, esto sin tener en cuenta otros costos como auxilio de transporte, vacaciones, cesantías, intereses de cesantías y prima de servicios. Por parte del empleado formal, este debe contribuir a salud y a pensiones, por lo que su salario se reduce en un $8 \%$. Finalmente, el trabajador independiente para poder contribuir a salud y a pensiones, el $40 \%$ de sus ingresos debe ser igual o mayor a un salario mínimo, ${ }^{8}$ lo que genera una disminución en sus ingresos en un 11,4\% aproximadamente. Se debe tener en cuenta, que los trabajadores independientes pagan en su totalidad la afiliación a salud y a pensiones. Por otro lado, se observa que para el año 2014 comienza a regir la Ley 1607 de Reforma Tributaria por lo que los costos no salariales del empleador se ven reducidos considerablemente, pasando de un $30,02 \%$ a un $12,5 \%$.

A partir de la reforma a la seguridad social (Ley 100 de 1993), los costos salariales aumentaron en 14 puntos porcentuales, generando así una pronunciada segmentación del mercado laboral. Se considera que los altos costos pueden aumentar la informalidad, ya que para algunas empresas o individuos no se justifica pagarlos debido a la poca rentabilidad que se obtiene de los aportes, y debido a que, en algunos casos, existe un vínculo muy bajo entre los aportes y los beneficios que generan. A su vez, los costos no salariales generan la segmentación del mercado laboral al introducir rigideces en el mercado formal. Este aumento de los costos puede verse reflejado en el aumento de la remuneración por trabajador o por la existencia de un salario mínimo que limita la transmisión total de estos, minimizando así la creación de empleo formal y la transición de empleos informales a empleos formales. Esto ha obligado a los individuos, en especial a los menos educados, que en su mayoría son los más pobres, a ubicarse en la informalidad a pesar de su deseo de ingresar al sector formal. Esta dinámica limita también el progreso social y previene la generación de ingresos sostenibles, además de tener efectos sobre la productividad y el crecimiento de la economía (Santa Maria et. al, 2009).

7. Los costos no salariales, representan todos los desembolsos monetarios que se utilizan para financiar algún gasto. Estos se calculan con base en el salario nominal de los trabajadores, usualmente como un porcentaje de éste.

8. Artículo 5 y 6 de la Ley 797 de 2003 
Tabla 4.

Costos no salariales en los que incurre el empleador, empleado formal y trabajador independiente, 2013 (pesos y porcentajes)

\begin{tabular}{|c|c|c|}
\hline Empleador & 2013 & 2014 \\
\hline Salario & 100 & 100 \\
\hline Salud & $8,50 \%$ & 0 \\
\hline Pensiones & $12 \%$ & $12 \%$ \\
\hline Riesgos Profesionales (1) & $0,522 \%$ & $0,522 \%$ \\
\hline ICBF & $3 \%$ & 0 \\
\hline SENA & $2 \%$ & 0 \\
\hline $\begin{array}{l}\text { Cajas de } \\
\text { compensación familiar }\end{array}$ & $4 \%$ & $4 \%$ \\
\hline Costos no salariales & $30,02 \%$ & $16,5 \%$ \\
\hline Empleado formal & 2013 & 2014 \\
\hline Salario & 100 & 100 \\
\hline Salud & $4 \%$ & $4 \%$ \\
\hline Pensiones & $4 \%$ & $4 \%$ \\
\hline Costos no salariales & $8 \%$ & $8 \%$ \\
\hline Trabajador independiente & 2013 & 2014 \\
\hline Salario (2) & $100(0.40)$ & $100(0.40)$ \\
\hline Salud (3) & $12,5 \%$ & $12,5 \%$ \\
\hline Pensiones (4) & $16 \%$ & $16 \%$ \\
\hline Costos no salariales & $\$ 28,5 \%$ & $\$ 28,5 \%$ \\
\hline
\end{tabular}

Fuente: Elaboración propia a partir de Duque 2008- 2013. Salarios y Prestaciones Sociales Mínimo legal - Año 2008-2013 - Colombia-.

\section{NOTAS}

Para este caso no se tuvo en cuenta otros costos en los que incurre el empleador, ya que estos varían de acuerdo con las necesidades de la empresa, tales como horas extras, dominicales y dotaciones (1): Los riesgos profesionales se clasifican según el tipo de 
riesgo: Riesgo I: 0,522\% Riesgo II: 1,044\%; Riesgo III: 2.436\%; Riesgo IV: 4.350\%; Riesgo V: $6.960 \%$. En este caso, para mayor facilidad solo se tuvo en cuenta el tipo de riesgo III. (2): Los trabajadores independientes sólo pueden cotizar a salud y a pensión si el $40 \%$ de sus ingresos es igual o mayor a un salario mínimo legal vigente . (3) y (4): El 12,5\% de cotización a salud y el 16\% de cotización a pensión se calcula sobre el $40 \%$ de los ingresos totales del trabajador independiente.

Otra vía que desincentiva la formalidad son los impuestos, Kugler y Kugler (2003) examinan los efectos de los cambios en los impuestos a la nómina sobre el empleo formal y los salarios para América Latina, y particularmente para el caso colombiano debido al gran aumento de los impuestos a la nómina durante las décadas de 1980 y 1990. Los autores encuentran que un incremento de $10 \%$ en los impuestos a la nómina ocasiona una disminución de los salarios formales entre 1,4\% y 2,3\% y disminuye el empleo entre $4 \%$ y $5 \%$. También señalan el hecho de que el débil vínculo entre los beneficios y algunos impuestos desincentiva el trabajo formal, y con base en este argumento consideran que políticas que reduzcan los impuestos a la seguridad social, principalmente sobre los que representan beneficios indirectos para el contribuyente, pueden ser efectivas.

Un método empleado para analizar los incentivos en el mercado laboral es a través de modelos de equilibrio parcial en donde se estudia el comportamiento de los agentes y sus interacciones para explicar los resultados que se obtiene en términos de precios y cantidades. Cuando en los mercados interviene el Estado y otro tipo de instituciones, el análisis debe extenderse a otras variables que se modifican como consecuencia de las reacciones de los agentes a estas intervenciones.

Levy (2010), analiza mediante un modelo de equilibrio parcial los efectos de programas sociales en el bienestar y la productividad de una sociedad que financia estos programas con impuestos a la nómina (esto lo hace para el caso particular de México). En este modelo los trabajadores maximizan su utilidad, eligiendo trabajo formal con seguridad social o trabajo informal con prestaciones de protección social. Las empresas eligen niveles de producción y empleo de manera tal que sus ganancias sean lo más elevadas posibles. Se supone, inicialmente, que los trabajadores tienen valoraciones iguales de los programas sociales. Entonces, las interacciones de las decisiones de empresas y trabajadores determinan la distribución de la fuerza de trabajo entre formales e informales (el autor los discrimina entre asalariados formales y no formales, autoempleados y comisionistas). Esta distribución, junto con las diferencias en prestaciones sociales, determina la producción, la productividad de los sectores formal e informal, y el grado de cumplimiento de los objetivos sociales del Gobierno. Estas decisiones también tienen implicaciones fiscales y financieras (Ver Anexo 2).

Levy (2010), encuentra que la segmentación del mercado, la coexistencia de programas de seguridad social y de protección social y la forma de financiación de estos sistemas genera reducción de empleo formal, aumento de empleo informal, menores valoraciones de la seguridad social, bajos niveles agregados de productividad, pérdidas de eficiencia a costa de cierta equidad e incrementos en los niveles de pobreza.

En varios países como en Colombia, el salario mínimo es mucho más elevado que el de equilibrio, lo que ocasiona desempleo e incentiva la informalidad. La inclusión de beneficios sociales netos de contribuciones, sobre todo cuando los paquetes son diferentes de los que pueden adquirir los auto-empleados, puede considerarse como un incremento del precio del trabajo y esto altera la demanda de trabajo formal. Además, si los trabajadores 
informales reciben beneficios de seguridad social sin realizar contribuciones, se reduce la oferta de trabajo formal; ocasionando desempleo e informalidad.

\section{MÉTODO}

Con base en un modelo convencional de equilibrio parcial, se pretende analizar y contabilizar un costo fiscal particular con respecto a un escenario ideal. Este escenario ideal consiste en suponer que los trabajadores que se encuentran laborando en la informalidad, medida en términos de no contribución de una parte de sus ingresos para salud, y que cuentan con ingresos laborales suficientes ${ }^{9}$ para contribuir al sistema de salud, lo harían a la tasa que corresponde a sus empleos si estuvieran laborando en el sector formal y de igual forma lo harían sus empleadores. Los trabajadores familiares contribuirían como formales asalariados y los jornaleros o peones como independientes. No consideramos las contribuciones que podrían realizar los trabajadores informales menores de 18 años. Estas contribuciones, que idealmente la economía hubiera percibido si su mercado laboral tuviera menores niveles de informalidad, se consideran una pérdida potencial para el sistema y es la que se pretende calcular.

En la Figura 5 se puede apreciar a partir de una situación de equilibrio en el mercado laboral como la introducción de un salario mínimo y posteriormente la reglamentación de las contribuciones a salud hacen que se demanden y se oferten cantidades de trabajo que no son compatibles, algunos empleadores y trabajadores se ven desincentivados a transar trabajo en el mercado formal lo que ocasiona desempleo y lleva a muchos agentes a transar en un mercado de trabajo informal. Algunos de estos trabajadores que se ubican en el mercado informal perciben ingresos que les permitirían contribuir para financiar el sistema de salud y disminuir la presión sobre el sistema para financiar las personas que realmente necesitan ser subsidiadas. La diferencia entre $\overline{\mathrm{W}}+\mathrm{c} y \overline{\mathrm{W}}-\mathrm{c}^{\prime}$ corresponde a la contribución que se deja de percibir por los trabajadores que se ubican en el sector informal a causa de los desincentivos que generan estos costos no salariales tanto del lado de la demanda como de la oferta.

Figura 5. Equilibrio parcial del mercado de trabajo

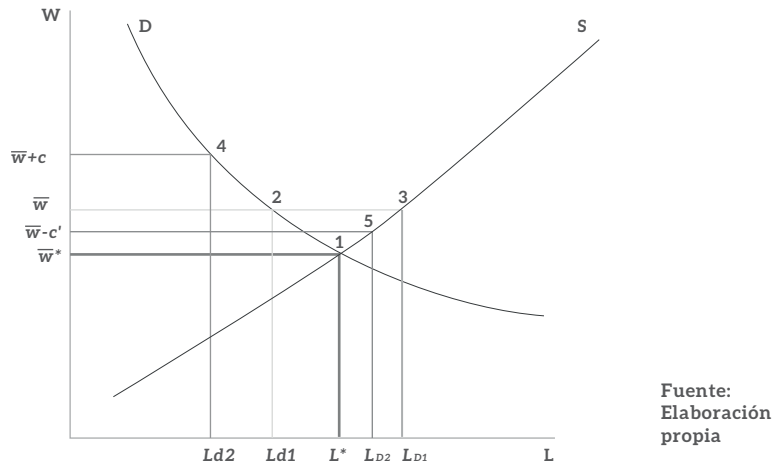

9. El artículo $6^{\circ}$ de la ley 797 de 2003 modificando el artículo $19^{\circ}$ de la ley 100 de 1993 establece que en ningún caso el ingreso base de cotización para trabajadores sin contrato laboral podrá ser inferior a un SMMLV. Con base en esto se adopta el supuesto de que los trabajadores que podrían formalizarse son aquellos que devengan un SMMLV o más. 
Para realizar el cálculo de la pérdida se tuvo en cuenta los datos de la Gran Encuesta Integrada de Hogares (GEIH), la cual es elaborada por el DANE para reunir información sobre las condiciones de empleo de las personas, las características generales como sexo, edad, estado civil y nivel educativo y las fuentes de ingresos. Esta encuesta proporciona información a nivel nacional, cabecera, resto, departamental, regional y para cada una de las capitales de los departamentos. Para facilidad en el análisis, se eligió el primer trimestre de la GEIH de los años 2008 hasta 2013 para cada una de las áreas, tanto el área urbana como el área rural. Se contó con una muestra aproximada de 65.000 familias para cada año, la cual es de carácter aleatorio y tiene representatividad a nivel nacional. Todos los cálculos fueron procesados en StataSE 12.

El principal objetivo de este trabajo consiste en calcular la pérdida financiera que pudo haber experimentado el Sistema General de Seguridad Social en Salud por la informalidad durante el período 2008-2013. Dado que dentro de la GEIH no se encuentra definido el nivel de SISBÉN para cada familia, fue necesario calcularlo basándose en la metodología utilizada por Miller, Pinto y Vera-Hernandez (2009). Este método consiste en definir el nivel del SISBÉN teniendo en cuenta cuatro tipos generales de información:

- Capital humano, características de los empleadores y beneficios

- Demográficos, ingresos y participación en el mercado laboral

- Características de la vivienda

- Acceso a los servicios públicos

En total este índice cuenta con 14 componentes, los cuales son categorizados según el tipo de respuesta. Cada respuesta obtiene un puntaje, y es a partir de la suma de estos que se obtiene el resultado final (Ver Tabla 5).

Tabla 5.

Metodología del SISBÉN

Capital humano, características de los empleadores y beneficios
1. Nivel educativo del jefe del hogar.

2. Media de escolarización de los miembros del hogar de doce años y mayores.

3. Tamaño de la empresa y la prestación de los beneficios del Seguro Social para el jefe de familia.
Demográficos, ingresos y participación en el mercado laboral
4. Proporción de niños de 6 años y menores (como proporción de los menores de dieciocho años).

5. Proporción de miembros del hogar que trabajan (como proporción de los mayores de doce).

6. Ingreso per cápita indexado al salario mínimo ${ }^{10}$ 
Tabla 5.

Metodología del SISBÉN

Características de la vivienda

Acceso a los servicios públicos
7. Número de habitaciones por persona.

8. Material principal de la pared.

9. Material principal del techo.

10. Material principal del piso.

11. Número de electrodomésticos ${ }^{11}$
12. Fuente de agua

13.2 Alcantarillado

14. Recolección de basuras

Fuente: Elaboración propia a partir de Miller, Pinto y Vera- Hernández (2009).

Dentro de estos componentes todos están disponibles en la GEIH entre los años 2008 y 2013, excepto el material principal del techo. Debido a esto, los puntos de corte fueron ajustados según la falta de este componente. Luego de obtener el puntaje total para cada familia, se definió el nivel de SISBÉN teniendo en cuenta los siguientes puntos de corte (Ver Tabla 6).

Tabla 6.

Puntos de corte del Sisbén Metodología III

\begin{tabular}{|c|c|c|c|}
\hline Programa & División & Nivel 1 & Nivel 2 \\
\hline \multirow{3}{*}{$\begin{array}{l}\text { Régimen } \\
\text { subsidiado }\end{array}$} & 14 ciudades & $0-47.99$ & $48.00-54.86$ \\
\hline & Resto urbano & $0-44.79$ & $44.80-51.57$ \\
\hline & Rural & $0-32.98$ & $32.99-37.80$ \\
\hline
\end{tabular}

Fuente: Elaboración propia teniendo en cuenta la Resolución 3778 de 2011 del Ministerio de la Protección Social.

10. Se tuvieron en cuenta los siguientes tipos de ingresos: Salario del primer empleo, horas extras, bonificaciones, ganancias netas (en caso de ser dueño de algún negocio) y el salario obtenido en el segundo trabajo (si lo tiene). No se tuvo en cuenta los ingresos generados por pagos en especie como alimentos, vivienda, electrodomésticos, subsidios, entre otros.

11. Entre lavadora, aire acondicionado, nevera, televisor y licuadora. 
Luego de definir el nivel de SISBÉN, se determina que las familias clasificadas en niveles 1 y 2 son aquellas que deben estar en el régimen subsidiado, mientras que los que están en nivel 3 en adelante son aquellos que deben hacer parte del régimen contributivo. Sin embargo, para efectividad del análisis también fue necesario tener en cuenta el nivel de ingresos.

En primer lugar, se procede a contar el número de personas que pertenecen a cada uno de los regímenes y también a los que no están afiliados a ninguno, teniendo en cuenta el factor de expansión ${ }^{12}$. En segundo lugar, se clasifica para cada año a las personas que pertenecen a cada uno de los regímenes pero que deberían estar en el régimen contributivo o en el régimen subsidiado. Para esto, fue necesario tener en cuenta el nivel del SISBÉN, si trabajan y si estos pagan o no por la afiliación a la seguridad social. Esta clasificación se hizo con el fin de identificar a las personas que generan pérdida en el sistema, que en este caso son aquellos que se encuentran en el régimen contributivo como beneficiarios, subsidiados que deberían estar en el régimen contributivo, y también las personas que están como no afiliadas pero que también deberían contribuir.

En tercer lugar, se procede a descontar a las personas que no representan ninguna pérdida para el sistema. Dentro de este grupo se encuentran los siguientes:
a. Personas que no trabajan.
b. Personas pertenecientes al régimen contributivo que paguen por su afiliación, ya sea en su totalidad o una parte sea pagada por su empleador, y además, que tengan un nivel de SISBÉN igual o mayor a 3.
c. Personas que estén afiliadas al régimen contributivo con nivel de SISBÉN 1 o 2.
d. Personas que pertenecen al régimen especial.
e. Personas menores de 18 años.
f. Personas que tienen un nivel de ingresos menor a un salario mínimo.

Finalmente, luego de obtener los datos de las personas que deberían contribuir pero que no lo hacen, se calcula la pérdida de la siguiente manera: primero, basándose en la posición ocupacional, se dividió la muestra en trabajadores formales y trabajadores independientes, considerándose como trabajadores formales aquellos empleados de empresa particular, empleados del Gobierno y los empleados domésticos; y trabajadores independientes, los trabajadores cuenta propia, el patrón o empleador y los jornaleros. Segundo, teniendo en cuenta esta clasificación se define que los trabajadores formales que aparecen en esta lista pueden contribuir. A partir de lo anterior se obtiene la pérdida, la cual resulta del total del máximo de contribución por persona, teniendo en cuenta el factor de expansión. La pérdida se describe en un intervalo de confianza, los cuales garantizan que el valor real está en un 95\% de confianza.

\section{RESULTADOS}

A lo largo del período en mención se registra un pequeño aumento en la cobertura de la población en el régimen subsidiado, pasando del 44,02\% en el año 2008 al 46,52\% en el año 2013. De igual forma, durante el mismo período se observa un incremento en el régimen contributivo y el régimen especial, que pasaron del 38,66\% al 40,59\% y del 1,96\%

12. Variable que indica cuántos individuos de cierto tipo hay en el país y se aplica cuando se quieren tener datos para casi el total de la población. 
al 2,75\%, respectivamente. A diferencia de los casos anteriores, vemos que la cantidad de personas no afiliadas ha disminuido, pasando de 15,41\% en 2008 a 10,05\% en 2013 (Ver Tabla 7). También se puede observar en el Tabla 8 la cobertura teniendo en cuenta la posición ocupacional de la población para el año 2013. Allí se encuentra que las personas que más contribuyen a salud son los empleados de empresa particular con un total de $92,47 \%$ y las personas que tienen mayor participación en el régimen subsidiado son los jornaleros representados por un total de 70,58\%.

Adicionalmente, se muestra (Ver Tabla 8) como la mayor cobertura se presenta entre empleados de la empresa particular y empleados del gobierno. Esto refleja que para las empresas con más de cien trabajadores las contribuciones son más notables, sin embargo a medida que vamos saliendo hacia empresas más pequeñas, específicamente hacia tipos de empleos menos estables como el empleado doméstico, la situación se va invirtiendo, teniendo una baja cobertura mediante el trabajo con un gran número de personas cubiertas como beneficiarios y muchas personas como subsidiadas, puesto que se va haciendo más probable la presencia de la informalidad.

Asimismo, se observa la evolución que ha tenido la cobertura en seguridad social entre el periodo 1997 a 2013 en los regímenes contributivo y subsidiado (Ver Tablas 8 y 9) para 1997 se observa que la mayor contribución a salud la realizaban los empleados del Gobierno, mientras que para 2013 la mayor contribución era de parte de los empleados de empresa particular. También se observa para 1997 que a medida que vamos saliendo a empresas más pequeñas observando los empleos menos estables se muestra menos cobertura mediante el trabajo y más número de personas cubiertas por el régimen subsidiado. Asimismo, a diferencia de los empleados del gobierno se observa un incremento generalizado en los contribuyentes de 1997 a 2013.

Tabla 7.

Colombia: cobertura de la seguridad social en salud por régimen 2008-2013. (Porcentajes)

\begin{tabular}{l|c|c|c|c|c}
\hline Año & $\begin{array}{c}\text { Régimen } \\
\text { subsidiado }\end{array}$ & $\begin{array}{c}\text { Régimen } \\
\text { contributivo }\end{array}$ & $\begin{array}{c}\text { Régimen } \\
\text { especial }\end{array}$ & No afiliados & $\begin{array}{c}\text { Población } \\
\text { total }\end{array}$ \\
\hline 2008 & $44,02 \%$ & $38,66 \%$ & $1,96 \%$ & $15,41 \%$ & 42.934 .407 \\
2009 & $46,17 \%$ & $37,67 \%$ & $2,30 \%$ & $13,72 \%$ & 43.536 .623 \\
2010 & $47,44 \%$ & $38,59 \%$ & $2,44 \%$ & $11,62 \%$ & 44.054 .638 \\
2011 & $46,02 \%$ & $39,51 \%$ & $2,63 \%$ & $11,74 \%$ & 44.549 .843 \\
2012 & $45,58 \%$ & $40,47 \%$ & $2,92 \%$ & $11,26 \%$ & 44.975 .279 \\
2013 & $46,52 \%$ & $40,59 \%$ & $2,75 \%$ & $10,05 \%$ & 45.575 .417 \\
\hline
\end{tabular}

Fuente: Elaboración propia teniendo en cuenta los datos de la GEIH para los años 2008-2013. 
Tabla 8.

Colombia: cobertura de la seguridad social en salud por posición ocupacional, 2013.

\begin{tabular}{|c|c|c|c|c|c|c|c|}
\hline & \multicolumn{2}{|c|}{$\begin{array}{l}\text { Régimen } \\
\text { contributivo }\end{array}$} & \multirow{2}{*}{$\begin{array}{l}\text { Régimen } \\
\text { Especial }\end{array}$} & \multirow{2}{*}{$\begin{array}{l}\text { Afiliación } \\
\text { mediante } \\
\text { el trabajo }\end{array}$} & \multirow{2}{*}{$\begin{array}{l}\text { Régimen } \\
\text { Subsidiado }\end{array}$} & \multirow{2}{*}{$\begin{array}{l}\text { No. } \\
\text { afiliados }\end{array}$} & \multirow{2}{*}{ Total } \\
\hline & $\begin{array}{l}\text { Contri- } \\
\text { buyentes }\end{array}$ & $\begin{array}{l}\text { Bene- } \\
\text { ficiarios }\end{array}$ & & & & & \\
\hline $\begin{array}{l}\text { Empleado de } \\
\text { empresa particular }\end{array}$ & $67,67 \%$ & $5,28 \%$ & $0,52 \%$ & $68,19 \%$ & $18,99 \%$ & $7,53 \%$ & $92,47 \%$ \\
\hline Empleado del Gobierno & $58,30 \%$ & $0,24 \%$ & $41,45 \%$ & $99,75 \%$ & $0,00 \%$ & $0,00 \%$ & $100,00 \%$ \\
\hline Empleado doméstico & $22,17 \%$ & $12,48 \%$ & $0,33 \%$ & $22,50 \%$ & $54,53 \%$ & $10,49 \%$ & $89,51 \%$ \\
\hline $\begin{array}{l}\text { Trabajador por } \\
\text { cuenta propia }\end{array}$ & $15,83 \%$ & $13,57 \%$ & $1,30 \%$ & $17,13 \%$ & $56,39 \%$ & $12,91 \%$ & $87,09 \%$ \\
\hline Patrón o empleador & $34,01 \%$ & $18,66 \%$ & $1,63 \%$ & $35,65 \%$ & $37,07 \%$ & $8,62 \%$ & $91,38 \%$ \\
\hline $\begin{array}{l}\text { Trabajador familia } \\
\text { sin remuneración }\end{array}$ & $5,42 \%$ & $16,18 \%$ & $1,10 \%$ & $6,53 \%$ & $65,49 \%$ & $11,80 \%$ & $88,20 \%$ \\
\hline $\begin{array}{l}\text { Trabajador sin } \\
\text { remuneración } \\
\text { empresas }\end{array}$ & $5,35 \%$ & $18,54 \%$ & $0,99 \%$ & $6,33 \%$ & $63,28 \%$ & $11.85 \%$ & $88.15 \%$ \\
\hline Jornaleros o peón & $8,87 \%$ & $3,12 \%$ & $0,05 \%$ & $8,91 \%$ & $70,58 \%$ & $17,39 \%$ & $82,61 \%$ \\
\hline Otro & $2,53 \%$ & $19,04 \%$ & $0,26 \%$ & $2,79 \%$ & $56,50 \%$ & $21,67 \%$ & $78,32 \%$ \\
\hline
\end{tabular}

Fuente: Elaboración propia teniendo en cuenta los datos de la GEIH para el año 2013.

Tabla 9.

Colombia: cobertura de la seguridad social en salud (Régimen contributivo y subsidiado) por posición ocupacional, 1997.

\begin{tabular}{lccc}
\hline & \multicolumn{2}{c}{ Régimen contributivo } & Régimen \\
& Contribuyentes & Beneficiarios & subsidiado \\
\hline $\begin{array}{l}\text { Empleado de } \\
\text { empresa particular }\end{array}$ & $63,20 \%$ & $7,60 \%$ & $6,10 \%$ \\
Empleado del Gobierno & $90,70 \%$ & $2,80 \%$ & $2,30 \%$ \\
Empleado doméstico & $17,20 \%$ & $6,80 \%$ & $19,80 \%$ \\
$\begin{array}{l}\text { Trabajador por } \\
\text { cuenta propia }\end{array}$ & $12,70 \%$ & $14,40 \%$ & $19,00 \%$ \\
Patrón o empleador & $31,70 \%$ & $14,20 \%$ & $12,00 \%$ \\
$\begin{array}{l}\text { Trabajador familia } \\
\text { sin remuneración }\end{array}$ & $3,10 \%$ & $10,10 \%$ & $29,80 \%$ \\
Jornaleros o peón & $4,80 \%$ & $2,50 \%$ & $37,30 \%$ \\
\hline
\end{tabular}

Fuente: Elaboración propia a partir de Restrepo y Salazar (2002). 
De otro lado, se muestra en el Tabla 10 que para 2013 las personas que deberían estar en el régimen contributivo incluidas sus familias es de 3.821.584; lo que implica que para 2013 estas personas deberían estar contribuyendo al sistema y no lo hacían. Igualmente, al realizar un análisis detallado se tiene que para 2013 el total de la Unidad de Pago por Capitación (UPC) que el sistema pagó por estas personas fue de \$1.983.531.884.198 entre el régimen subsidiado y contributivo. Sin embargo, si estas personas que deberían estar en el régimen contributivo lo hubieran hecho, se tendría que para 2013 la UPC que el sistema hubiera pagado por estas personas sería \$2.174.267.137.095. claramente se observa que el sistema hubiera tenido que pagar más por la UPC de estas personas si en realidad hubieran estado en el régimen contributivo, pero al analizar el lado de las contribuciones de estas personas el sistema general hubiera compensado ese incremento en la UPC, por tal motivo no se hubiera generado una perdida para el sistema.

Tabla 10.

Personas que están en cada uno de los regímenes pero que deberían estar en el régimen contributivo o en el régimen subsidiado 2013

\footnotetext{
Están

Deberían estar en el Régimen Contributivo

Régimen Contributivo

Régimen Subsidiado

640.054

3.181 .529

Total

3.821 .584

Fuente: Elaboración propia teniendo en cuenta los datos de la GEIH para el año 2013.

De igual manera, se observa en el Tabla 11 el número total de personas que por sus características deben estar contribuyendo, pero no lo hacen. Asimismo, entre 2008 y 2013 se ha incrementado los trabajadores informales con capacidad de contribuir al sistema. Cabe mencionar que entre el periodo 2009 a 2010 tanto los beneficiarios del régimen contributivo como el subsidiado tuvieron una disminución pasando de 3.389.043 a 2.986.529; como se mencionó anteriormente (Ver Figura 2) esta reducción se debió a la combinación de crecimiento económico, a las iniciativas legislativas y a las reformas institucionales implementadas durante este periodo.
} 
Tabla 11.

Trabajadores informales que podrían contribuir, 2008-2013

\begin{tabular}{l|c|c|c|c|cc}
\hline & 2008 & 2009 & 2010 & 2011 & 2012 & 2013 \\
& & & & & & \\
& & & & & & \\
$\begin{array}{l}\text { Beneficiarios } \\
\text { régimen Contributivo }\end{array}$ & 534.304 & 548.080 & 512.516 & 535.705 & 632.613 & 640.054 \\
Subsidiados & 2.315 .339 & 2.840 .963 & 2.474 .013 & 2.780 .874 & 3.063 .245 & 3.181 .530 \\
Total & 2.849 .643 & 3.389 .043 & 2.986 .529 & 3.316 .579 & 3.695 .858 & 3.821 .584 \\
\hline
\end{tabular}

Fuente: Elaboración propia teniendo en cuenta los datos de la GEIH para el período 2008-2013.

Como resultado se tiene que la pérdida que obtuvo el sistema para el año 2013 estuvo entre 2.7 y 2.9 billones (Ver Tabla 12). También se muestra que la perdida ha ido incrementando durante el periodo 2008 a 2013, ya que la informalidad fue incrementando. Igualmente, se analiza la posición ocupacional de las personas que generan la perdida al sistema y se observa que la mayor participación la tiene los trabajadores por cuenta propia con 1.253 .425 personas, seguido de las empresas particulares con 588.799 personas (Ver Tabla 13). Puede deducirse que esta mayor participación de los trabajadores cuenta propia la conforman las personas que se encuentran en la informalidad y por tanto no contribuyen al sistema.

Tabla 12.

Pérdida del Sistema General de Seguridad Social en Salud por la informalidad, Gasto del sistema de salud (GSS) y la pérdida como porcentaje del GSS, 2008-2013 (En porcentajes y millones de pesos)

\begin{tabular}{l|cc|c|cc}
\hline Año & \multicolumn{2}{|c}{$\begin{array}{c}\text { Pérdida } \\
\text { 95\% intervalo de confianza }\end{array}$} & $\begin{array}{c}\text { Gasto del } \\
\text { sistema }\end{array}$ & Pérdida/Gasto del sistema \\
\hline 2008 & 1.670 .000 & 1.840 .000 & 22.554 .521 & $7,40 \%$ & $8,16 \%$ \\
2009 & 1.980 .000 & 2.160 .000 & 25.980 .609 & $7,62 \%$ & $8,31 \%$ \\
2010 & 1.970 .000 & 2.160 .000 & 27.113 .528 & $7,27 \%$ & $7,97 \%$ \\
2011 & 2.140 .000 & 2.320 .000 & 30.490 .845 & $7,02 \%$ & $7,61 \%$ \\
2012 & 2.460 .000 & 2.640 .000 & 32.280 .470 & $7,62 \%$ & $8,18 \%$ \\
\hline 2013 & 2.700 .000 & 2.900 .000 & 37.737 .171 & $7,15 \%$ & $7,68 \%$ \\
\hline
\end{tabular}

Fuente: Elaboración propia a partir de la información de la GEIH, del Banco Mundial y del Banco de la República. 
Tabla 13.

Posición ocupacional de las personas que generan pérdida, 2013

Posición ocupacional

\begin{tabular}{l|c}
\hline Empleado de empresa particular & 588.799 \\
Empleado doméstico & 30.193 \\
Trabajador por cuenta propia & 1.253 .425 \\
Patrón o empleador & 303.875 \\
Jornaleros o peón & 69.095 \\
\hline Total & 2.245 .387
\end{tabular}

Fuente: Elaboración propia teniendo en cuenta los datos de la GEIH para el período 2013.

En Colombia, el gasto del sistema de salud ha venido aumentando, pasando de 22,55 billones en el 2008 a 37.74 billones en el 2013 (en términos nominales) (Ver Tabla 12). Los gastos del sistema de salud fueron tomados de los Informes de Gestión y de Actividades que el Ministerio de Salud y Protección presenta al Congreso de la República e incluye los gastos en el régimen contributivo, régimen subsidiado, prestación de servicios a la población pobre no asegurada, gastos de salud pública y promoción y prevención, recobros por medicamentos no POS , fallos de tutela, reconocimiento de servicios no POS, subcuenta de Eventos Catastróficos y Accidentes de Tránsito, ECAT, la subcuenta de garantías para la salud del Fosyga y los gastos de funcionamiento del SGSSS. Si se considera la pérdida como proporción de este gasto se observa que esta ha permanecido casi constante a lo largo del período establecido, con un porcentaje promedio entre 8,12\% y 8,71\%. Este valor es significativo con respecto al valor del gasto del sistema de salud (Ver Figura 6). Además, esta pérdida está en promedio entre un 0,40\% y 0,43\% del Producto Interno Bruto, PIB (Ver Tabla 14).

Cálculos preliminares del trabajo de Clavijo y Torrente, 2008, indican que el déficit que acumula el sistema anualmente está en el rango de $1.1 \%$ y $2.1 \%$ del PIB, donde parte de este puede ser explicado por la pérdida asociada a la informalidad. Adicionalmente, para dimensionar el tamaño de la pérdida, con lo que se dejó de percibir en el año 2013 se hubieran podido financiar la prestación de los servicios a la población pobre no asegurada, cerca del $80 \%$ de los recobros por medicamentos No-POS y fallos de tutela. 
Figura 6. Valor de la pérdida del SGSSS y el Gasto en salud.

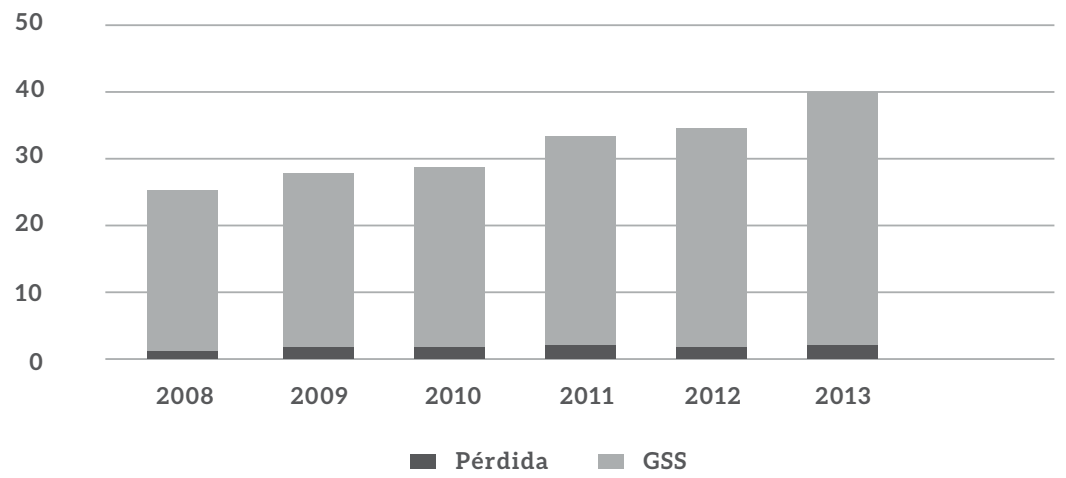

Fuente: elaboración propia a partir de Datos tomados de la GEIH, Banco Mundial y Banco de la República.

Tabla 14.

Pérdida del SGSSS y Gasto en salud como porcentaje del PIB, 2008-2013.

\begin{tabular}{l|ccc}
\hline Año & \multicolumn{2}{c}{ Pérdida \% PIB } & GSS \% PIB \\
\hline 2008 & $0,28 \%$ & $0,31 \%$ & $4,70 \%$ \\
2009 & $0,32 \%$ & $0,35 \%$ & $5,15 \%$ \\
2010 & $0,29 \%$ & $0,32 \%$ & $4,98 \%$ \\
2011 & $0,38 \%$ & $0,39 \%$ & $4,92 \%$ \\
2012 & $0,32 \%$ & $0,34 \%$ & $4,85 \%$ \\
2013 & $0,32 \%$ & $0,34 \%$ & $5,34 \%$ \\
\hline Promedio & $0,32 \%$ & $0,34 \%$ & $4,99 \%$
\end{tabular}

Fuente: Elaboración propia a partir de los datos tomados de la GEIH, Banco Mundial y Banco de la República.

\section{CONCLUSIONES}

Los resultados obtenidos en este trabajo muestran que la pérdida del sistema de salud es representativa dentro de los gastos del sistema de salud; lo que indica que la informalidad además de reducir la productividad y ubicar la economía en un punto subóptimo de producción, representa un importante costo financiero para el sistema. De igual forma, el costo fiscal que se ha estimado como proporción de los gastos en salud, no varía en el período de análisis, esto puede deberse a una de dos situaciones: la primera, es debido a que no se están generando reformas que desincentiven la informalidad y reduzcan 
la pérdida, y la segunda a que los determinantes de esta pérdida están variando en direcciones contrarias y se contrarrestan.

Es importante resaltar que este panorama es limitado, pues no se consideran los otros programas de protección social por los que los trabajadores formales también deben contribuir, ni los impuestos indirectos que también están o estaban atados a la condición laboral. Además, porque no solo hay empleados informales también hay empresas informales que responden a otros incentivos y a otros tipos de regulaciones. No se debe olvidar que hay cierto componente estructural en la informalidad que no solo se anula con intentar cambiar las regulaciones institucionales.

Por otro lado, hay situaciones que agravan este panorama, como la igualación de los Planes Obligatorios de Salud (POS) que la sentencia T760/2008 ha obligado a cumplir. Otras, en cambio, intentan atenuar un poco la situación, por ejemplo, la reforma 1607 de 2012 ha eliminado las contribuciones que los empleadores realizaban a la Seguridad Social por los empleados que devengan menos de 10 SMMLV, lo que puede ser un importante incentivo para la generación de empleo formal y reducción de la informalidad. Otro importante incentivo a la formalidad es el decreto 3047 de 2013 que reglamenta la movilidad entre regímenes para trabajadores (niveles 1 y 2 del SISBÉN) y sus familias. Sin embargo, es un poco pronto para calcular dichos efectos.

Este estudio cuenta con algunas limitaciones que pueden resolverse en futuros trabajos. Por un lado, se puede proponer un modelo econométrico en el que se muestre el impacto que causa la informalidad y la igualación de las UPC sobre la pérdida del sistema de salud. Asimismo, se puede estructurar de forma más adecuada el modelo de equilibrio parcial, teniendo en cuenta las debidas ecuaciones que se derivan de este planteamiento.

De los hallazgos recién expuestos se derivan las siguientes recomendaciones de política. En el corto plazo, se deben diseñar políticas que ayuden a estructurar el sistema de salud. Se puede contemplar, por ejemplo, la cobertura universal independientemente de la posición ocupacional y financiamiento con otro tipo de impuestos, y esto estaría en línea con la reforma estatutaria aprobada recientemente, pero inevitablemente los recursos tienen que reponerse con otro impuesto que genera distorsiones en otros sectores. Se debe evaluar las distorsiones asociadas a diferentes tipos de impuestos y elegir la que genere menor pérdida social.

Por último, dada la implicación que tiene la informalidad en el SGSSS, es necesario continuar con el análisis de esta en los años siguientes a 2013. Así como realizar un estudio de las implicaciones tanto positivas como negativas que ha venido dejando la Ley 1607 de 2012 de Reforma Tributaria.

\section{REFRENCIAS BIBLIOGRÁFICAS}

Bernal, Óscar y Guitierrez, C. (2012). La salud en Colombia: Logros, retos y recomendaciones. La salud en Colombia: logros retos y recomendaciones. Retrieved from http://boletinespunivalle.info/files/esss/la_salud_en_colombia_Uniandes.pdf

Camacho, A., Conover, E., \& Hoyos, A. (2013). Effects of Colombia 's Social Protection System on Workers ' Choice between Formal and Informal Employment, (August), 446-466. https:// doi.org/10.1093/wber/lht028 
Cárdenas, M., \& Mejía, C. (2007). Informalidad en Colombia: Nueva Evidencia. Documentos de Trabajo, (35), 43. Retrieved from http://www.fedesarrollo.org.co/wp-content/ uploads/2011/08/WP-No.-35-Informalidad-en-Colombia-M-C?rdenas-y-C-Mej?a-WP35.pdf

Clavijo, S., \& Torrente, C. (2008). El Déficit Fiscal de la Salud en Colombia: Estimación de su Pasivo Actuarial. América Lat. Retrieved from http://www.anif.co/sites/default/files /investigaciones/pasivoactuarial-salud_08.pdf

Colombia. Banco de la República. (2016). TERCER INFORME TRIMESTRAL DE MERCADO LABORAL 2016: IMPACTO DE LA REFORMA TRIBUTARIA DE 2012 SOBRE LA INFORMALIDAD, 1-8. Retrieved from http://www.banrep.gov.co/es/emisor-208

Colombia. Ministerio de Salud y protección Social. (2018). Sistema Integral de Información de la Protección Social. Retrieved from http://www.sispro.gov.co/

Currie, J., \& Madrian, B. C. (1999). Health, health insurance and the labor market. In Handbook of Labor Economics (Vol. 3, pp. 3309-3416). https://doi.org/10.1016/S1573-4463(99)30041-9

DANE. (2009). Departamento Administrativo Nacional de Estadística Dirección de Regulación, Planificación , Estandarización y Normalización. Metodologia Informalidad Gran Encuesta Integrada De Hogares - Geih, 1-12. https://doi.org/1. Departamento Administrativo Nacional de Estadística (DANE) [Internet]. [cited 2015 Mar 5]. Available from: http://www.dane.gov.co/index.php/poblacion-y-demografia/censos

DANE. (2018). Boletín técnico Medición de empleo informal y seguridad social Trimestre enero marzo 2018 Boletín técnico, 1-12. Retrieved from https://www.dane.gov.co/index.php/ estadisticas-por-tema/mercado-laboral/empleo-informal-y-seguridad-social

Duque, C. (2014). Salarios y Prestaciones Sociales - Mínimo legal - Año 2008-2013 -Colombia-. Retrieved from http://consultas-laborales.com.co/

Fedesarrollo. (2011). Efectos de ley 100 en salud. Fedesarrollo. Retrieved from https://www. repository.fedesarrollo.org.co/bitstream/handle/11445/65/LIB_2011_Efectos de la ley 100 en salud_Completo.pdf?sequence=2\&isAllowed=y

Fernández, C., Villar, L., Gómez, N., \& Vaca, P. (2017). Taxonomía de la informalidad en América Latina, (75). Retrieved from http://www.repository.fedesarrollo.org.co/bitstream/ handle/11445/3476/WP_2017_No_75.pdf?sequence=1\&isAllowed=y

García, F., Mujica, A. V., \& Santa María, M. (2009). Los costos no laborales y el mercado laboral: Impacto de la reforma de salud en Colombia. Fedesarrollo Documentos de Trabajo, (43). Retrieved from http://hdl.handle.net/11445/252

Kugler, A., \& Kugler, M. (2003). The labor market effects of payroll taxes in a middle-income country: evidence from Colombia. Discussion Paper Series Centre for Economic Policy Research London, (852), ALL. Retrieved from http://eprints.soton.ac.uk/33492/

Levy, S. (2010). Good Intentions, Bad Outcomes: Social Policy, Informality and Economic Growth in Mexico. Retrieved from https://books.google.com.co/books?hl=es\&lr=\&id=2qXFY2KiQ34 C\&oi=fnd\&pg=PP1\&dq=citar+Good+Intentions,+Bad+Outcomes:+Social+Policy,+Informality +and+Economic+Growth+in+Mexico.\&ots=sOg3rkC5kX\&sig=WzWk9eZ1SCi_FyQ7L1g_ VEu9EZ8\#v=onepage\&q\&f=false 
Miller, G., Pinto, D., \& Vera-Hernandez, M. (2009). High-powered incentives in developing country health insurance: evidence from Colombia's regimen Subsidiado, (October).

Morales, Leonardo y Medina, C. (2016). Assessing the Effect of Payroll Taxes on Formal Employment: The Case of the 2012 Tax Reform in Colombia.

OIT. (2014). Evolución del empleo informal en Colombia: 2009-2013.

Perry, G. E., Maloney, W. F., Arias, O. S., Fajnzylber, P., Mason, A. D., \& SaavedraChanduvi, J. (2007). Informalidad: Escape y Exclusión. The International Bank for Reconstruction and Development / The World Bank. Retrieved from http://documentos.bancomundial.org/curated/es/889371468313790669/ Informalidad-escape-y-exclusion\%0Ahttp://www-wds.worldbank.org/ external/default/WDSContentServer/WDSP/IB/2008/08/25/000333037_200 80825002558/Rendered/PDF/400080PUBOSPAN101OFFICIALOUSEOONLY1.

Rodríguez, D. (2014). LEY 1607 DE 2012 DE REFORMA TRIBUTARIA EN COLOMBIA: UN ANÁLISIS DE EQUILIBRIO GENERAL COMPUTABLE.

Uribe, Jose y Ortiz, C. (2006). Visiones sobre la informalidad y una propuesta alternativa. In Informalidad laboral en Colombia 1988-2000. Evolución, teorías y modelos (pp. 21-54). Cali: Editorial Universidad del Valle. 


\section{ANEXOS}

Tabla A1.

Colombia: Iniciativas para promover la formalización, 2000 - 2014

\begin{tabular}{lll}
\hline Año & Instrumentos & \multicolumn{1}{c}{ Descripción } \\
\hline 2000 & Ley 590 & Ley Mipyme. \\
\hline 2004 & Ley 905 & Ley de promoción del desarrollo de la Mipyme. \\
\hline 2007 & Ley 1151 & Plan Nacional de Desarrollo 2006-2010. \\
\hline 2010 & Ley 1233 & Ley de promoción y desarrollo de la Mipyme. \\
\hline 2011 & Ley 1429 & Ley de Formalización y Generación de Empleo \\
\hline
\end{tabular}

Plan de acción

para derechos

laborales (TLC USA)

Ruedas de servicios

para la formalización

\begin{tabular}{|c|c|c|}
\hline 2012 & Ley 1607 & Reforma Tributaria \\
\hline & Resolución 2272 & Herramienta anterior a Ley 1610. \\
\hline & $\begin{array}{l}\text { Brigadas para la } \\
\text { formalización }\end{array}$ & \\
\hline & $\begin{array}{l}\text { Beneficios Económicos } \\
\text { Periódicos }\end{array}$ & \\
\hline & $\begin{array}{l}\text { Proyectos por sectores } \\
\text { y regiones }\end{array}$ & \\
\hline
\end{tabular}

2013

Ley 1610

Ley 1636

Resolución 321

Decreto 2616

Decreto 721
Regula las inspecciones laborales y los acuerdos de formalización Laboral.

Mecanismo de Protección al Cesante.

Requisitos para acuerdos de formalización laboral.

Cotización de seguridad social por semanas o múltiplos

Obligación de afiliar al servicio doméstico en una caja de compensación familiar.

2014

Decreto 567

Red Nacional de Formalización Laboral

Fuente: Farné (2013) e Isaza (2014). Tomado de Programa de Promoción de la Formalización en América Latina y el Caribe (FORLAC), OIT (2014). 
Figura A2. El mercado de trabajo con valoración completa de la seguridad social

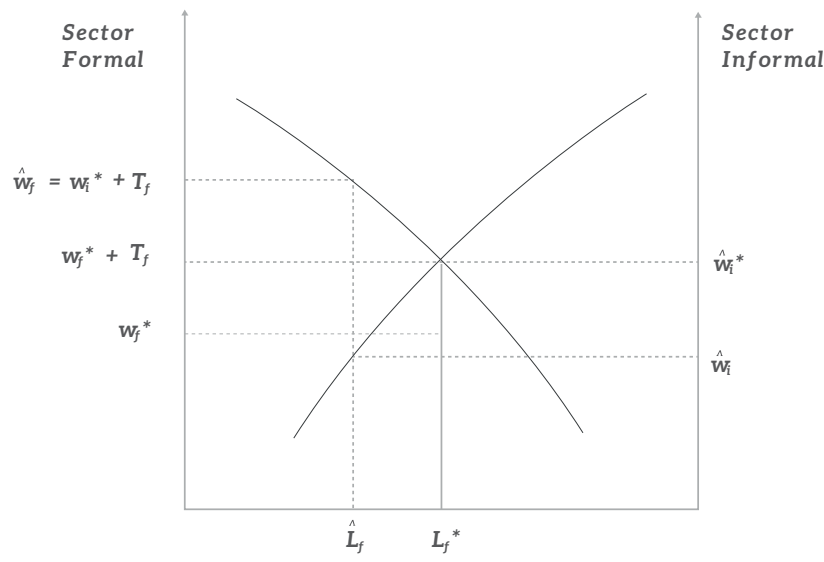

Fuente: Levy, 2010, pág. 176. 